\title{
THE PREVALENCE OF LOW BACK PAIN IN COMMERCIAL MOTOR DRIVERS AND PRIVATE AUTOMOBILE DRIVERS
}

\author{
Journal website at; \\ http://mrtbjournal.org/index.p/p/njinr/issue/current/showToc
}

\author{
*DO ODEBIYI, *DCOGWEZI, **BOA ADEGOKE \\ Departments of Physiotherapy, *College of Medicine of the University of Lagos, Lagos State; \\ **College of Medicine, University of Ibadan, Oyo State
}

\author{
Correspondence \\ Daniel O Odebiyi \\ femiodebiyi@yahoo.com
}

\section{SUMMARY}

Background: The low back is susceptible to injury (pain) because it supports most of the body weight. Prolonged sitting and being sedentary are some of the risk factors to developing low back pain (LBP). This study was designed to determine and compare the prevalence of LBP in Commercial Motor Drivers (CMD) and Private Automobile Drivers (PAD).

Materials and Method: Five hundred males (250-CMD and 250-PAD) participated in the survey. The participants were made to complete a 33-item closed ended questionnaire. The questionnaire collected information on the respondents' biodata, driving, back pain and the effects of driving on the low back (LB). The questionnaire was self administered.

Results: The results showed that LBP was a major problem among these groups of drivers. The 12-month prevalences of LBP among the CMD and PAD were $96 \%$ and $88 \%$ respectively. Twelve-month prevalence of LBP was significantly $(p<0.05)$ higher in the CMD. Sixty four percent and $42 \%$ of the CMD and PAD attributed the cause of their back pain to the length of time spent sitting when driving.

Conclusion: Low back pain was a major problem among the respondents; but was experienced more among CMD. The higher prevalence of LBP in CMD was attributed to the length of time spent sitting when driving.

KEY WORDS: Prevalence, low back pain, Commercial Motor Drivers, Private Automobile Drivers.

\section{INTRODUCTION}

Low back pain (LBP) is usually a symptom of some underlying conditions, most common LBP often results from misuse or abuse of the back consequent to habitual wrong posture, chronic strain, weakened back muscles and stress tension fatigue syndrome (Olaogun, 1999). 1t is one of the most commonly treated disorders in out-patients' Thysiotherapy Clinics worldwide (Malluf et al, 2000) and has been found to have a significant impact on functional ability thereby restricting occupational activities with marked socioeconomic repercussion (van Tulder, 2002). The low back supports most of the body's weight hence; it is susceptible to injury (Cassidyl, 1998). Improper sitting for extended periods (i.e. prolonged sitting) and being sedentary have also been found to increase the risk of developing LBP (Cohen, 1989; Cassidyl, 1998).

It is difficult to pin point the root cause of LBP, however, poor muscle tone, joint problems, torn muscles and ligament (Cohen, 1989), prolonged sitting and being sedentary have been reported to increase the risk of development of mechanical LBP (McKenzie, 1990). Long hours of driving have been noted to contribute to a herniated disc due to the vibration caused by automobiles (Frymoyer and Cats-Baril, 1991; Hedge, 2002). A high risk of developing LBP has been reported among men who drive for at least 4-hours a day. The lumbar spine has a natural resonance frequency of $4-5 \mathrm{~Hz}$ and when driving, vibration causes the body to resonate at that frequency (Hedge, 2002). The low back becomes vulnerable to the strain and injuries due to the vibration of the whole body.

The car seat has been indicted as contributory to the development of LBP, particularly, in people who drive for long hours (McKenzie, 1990; Boshuizen et al, 1990; Hedge, 2002). The car seat pan and its backrest usually keeps the driver's hip in an angle $90^{\circ}$ or less, thus predisposing the lower lumbar discs to a great deal of pressure; the resultant forces subsequently contribute to injury of the LB and degeneration of the lumbar spine (Hedge, 2002). Loss of rigidity or sagging of the car seat (usually due to wear and tear) has also been suggested to predispose the low back to injury, as it has been established that this causes the knees to be elevated higher than the pelvis (Boshuizen, 1990; Hedge, 2002). This may result in the concentration of the gravitational forces of the upper part of the body at the lower lumbar spine (Hedge, 2002).

Low back pain of mechanical origin is usually aggravated and perpetuated by poor sitting posture. and patients with LBP generally report an increase in pain intensity with movement towards lumbar Jordosis which is the normal curvature of the lumbar region (McKenzie, $1090)$, Eonsequently, poor sitting that reduces the lumbar 
lordosis usually places the ligamental structures of the back under stretch (Mckenzie 1981; Sinaki and Morki 2000). It is also believed that excessive periods spent in a poor posture may be contributory to the deterioration of the lower interverbral discs with consequent pain in the low back (Low and Reed, I996). Traffic congestion is a phenomenon commonly seen on our roads; this usually leads to the long hours of driving experienced by both commercial and private drivers in Nigeria. This present study was therefore designed to determine and compare the prevalence of LBP in CMD and PAD. The study also sought to examine the nature and causes of LBP among the participants, and the back care knowledge of the participants in the two groups.

\section{MATERIALSAND METHOD \\ Participants}

Five hundred (500) male drivers participated in this survey. The participants were 250 commercial motor drivers (CMD) who drove for more than 3-hours per day, and were regarded as long distance drivers and 250 private automobile drivers (PAD) who drove privately owned car, and were regarded as short distance drivers. Participants were recruited from commercial bus terminals (motor parks) and corporate organisations around Lagos metropolis. The participants were aged 30 years and above.

\section{Materials}

The only instrument used during the course of this study was a 33 item closed ended questionnaire. The questionnaire has four sections A, B, C and D. Section A comprised of questions on the participants' clinical and demographic data, section $\mathrm{B}$ comprised questions on driving and LBP; while sections $C$ and D collected information on the influence of driving on LBP for CMD and PAD respectively. The questionnaire was adapted from those used in previous studies (Hedge, 2002, Akinpelu and Odebiyi, 2004). Copies of the questionnaire were sent to three experts in the design of questionnaire to ascertain the content validity and corrections were made according to their input. Thereafter, the questionnaire was pilot tested. The questionnaire was written in English language.

\section{Method}

The purpose of the study was explained to the chairpersons and chief executives in charge of the motor parks and Corporate Organisations in order to obtain their approval. Copies of the questionnaire were then distributed by hand to the participants who consented to participate in the study, and were administered by the researchers as the participants were available, on one on - one basis. Five hundred (500) copies of the questionnaire were distributed, and there was a hundred percent response rate, probably due to the method of distribution of the copies of the questionnaire. All the respondents who volunteered had their blood pressure measured; they were also given some vitamin $\mathrm{C}$ tablets and paracetamol as incentives.

\section{Statistical Method}

The required information was extracted and the data obtained were presented using descriptive statistics of mean, standard deviation and percentages. An inferential statistics of chi square was used to determine significant difference between variables at 95 percent confident interval.

\section{RESULTS}

- Age and Plyysical Characteristics:

Table 1 shows the age and physical characteristics of the respondents. Independent student t-test showed that there was no statistically significant difference between the physical characteristics of CMD and PAD. This may implies that the two groups were similar in age and physical characteristics.

\section{- History of Low Back Pain:}

The 12-month prevalence of LBP in the CMDs and PADs were $96 \%$ and $88 \%$ respectively (table 2 ). In $35 \%$ of the respondents, LBP was not serious enough to require medications while it was that serious in $45 \%$ of the respondents. Also in about $20 \%$ of the respondents the LBP was serious enough for the respondents to seek hospital treatment. None of the respondents was however hospitalised for treatment because of LBP. Majority of the participants in the CMD group (55\%) and PAD group (52\%) who reported having LBP experienced LBP when retiring to sleep in the evening. Eighty-eight percent and $62 \%$ of the participants in the CMID and PAD groups respectively had no formal knowledge of proper handling of the back respectively. Of the participants in the CMD and PAD, only $12 \%$ and $38 \%$ of CMD and PAD had formal knowledge on the proper handling of the back (Figure 1).

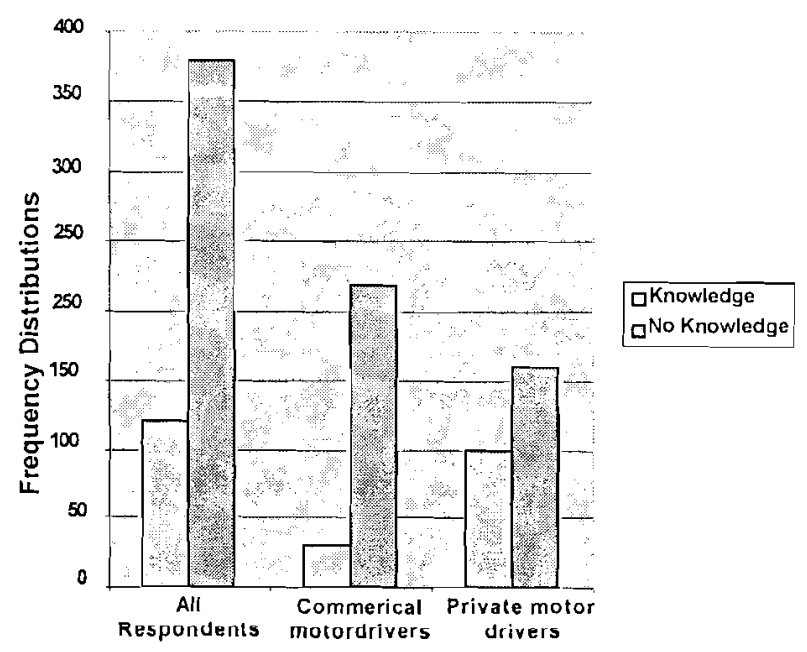

Figure 1: Bar Chart Showing the Proportion of the Respondents with Formal Knowledge of Back Care. 
Table 1: Demographic Data of the Respondents

\begin{tabular}{lllll}
\hline & $\begin{array}{l}\text { Long Distance } \\
\text { Drivers } \\
\text { Means } \pm \text { SD }\end{array}$ & $\begin{array}{l}\text { Private Auto } \\
\text { drivers } \\
\text { Means } \pm \text { SD }\end{array}$ & t & P-value \\
\hline Age(years) & $41.07 \pm 8.10$ & $40.28 \pm 7.22$ & 1.13 & 0.26 \\
Weight $(\mathrm{kg})$ & $69.08 \pm 7.70$ & $69.94 \pm 7.61$ & 1.20 & 0.23 \\
Height $(\mathrm{m})$ & $1.68 \pm 0.10$ & $1.68 \pm 0.09$ & 0.10 & 0.99 \\
$\mathrm{BMI}\left(\mathrm{kg} / \mathrm{m}^{2}\right)$ & $24.45 \pm 6.17$ & $24.78 \pm 5.67$ & 1.22 & 0.24 \\
\hline
\end{tabular}

Keys:

SD - Standard deviation

$\mathrm{BMI}$ - Body mass index

Table 2: Twelve-Month Prevalence of Low Back Pain among the Respondents

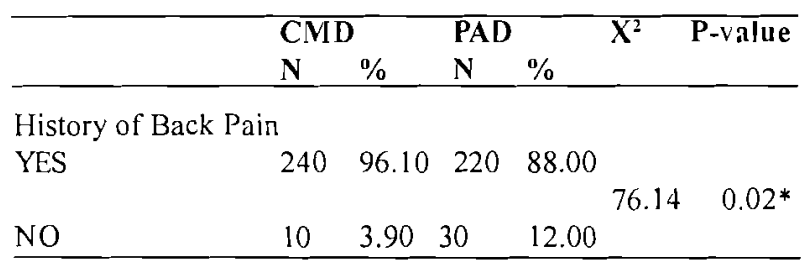

*Significant Difference at $\mathrm{P}<0.05$

Keys:

$\mathrm{CMD}=$ Commercial Motor drivers

$\mathrm{PAD}=$ Private Automobile Drivers

\section{- Nature and Causes of Low Back Pain:}

The onset of LBP was gradual in about $90 \%$ of the respondents. Forty six percent (230) of the respondents experienced LBP when they were stressed up, $122(27 \%)$ experienced LBP after driving for more than 2 hours and $108(23 \%)$ experienced LBP all the time (Figure 1). The majority $(65 \%)$ of the PADs were driving for between 1 and 2 hours while majority (76\%) of the CMDs group were driving for more than 3 hours daily (table 3 ). One way analysis of variance showed that there was a significant difference between the two groups (table 3). Seventy-two percent of the participants in the CMD group compared to $28 \%$ of those in the PAD group who experienced LBP attributed the cause of their LBP to the length of time spent driving (table 4 ). The majority $(64 \%)$ of the participants in the CMD group attributed the cause of their back pain to the length of time spent sitting when driving contrary to the $42 \%$ of those in the PAD group (Table 4).

Table 3: Summary of the Statistic of Length of Time Spent Driving by the Respondents

\begin{tabular}{|c|c|c|c|c|c|c|}
\hline \multirow{2}{*}{$\begin{array}{l}\text { Hours of } \\
\text { Driving }\end{array}$} & \multicolumn{2}{|c|}{ CMD } & \multicolumn{2}{|c|}{$\overline{\mathrm{PAD}}$} & \multirow[t]{2}{*}{$x^{2}$} & \multirow{2}{*}{$\overline{\text { P-value }}$} \\
\hline & $\mathbf{N}$ & $\%$ & $\mathbf{N}$ & $\%$ & & \\
\hline$\leq 1$ & 42 & 16.60 & 88 & 35.20 & & \\
\hline$>1<3$ & 55 & 22.00 & 160 & 64.80 & 76.14 & $<0.001 *$ \\
\hline$\geq 3$ & 190 & 76.00 & 0 & 0 & & \\
\hline
\end{tabular}

*Significant Difference at $\mathrm{P}<0.05$

Keys:

$\mathrm{CMD}=$ Commercial Motor drivers

$\mathrm{PAD}=$ Private Automobile Drivers
Table 4: Summary of the Statistic of the Respondents who Attributed the Cause of the Back Pain to Long Hours of Driving

\begin{tabular}{lllll}
\hline & \multicolumn{2}{c}{ CM D } & \multicolumn{2}{c}{ PA D } \\
& $\mathbf{N}$ & $\%$ & N & $\%$ \\
\hline Yes & 236 & 72.40 & 90 & 27.60 \\
No & 4 & 3.00 & 130 & 97.00 \\
\hline
\end{tabular}

Keys:

CMD - Commercial Motor Drivers

PAD - Private Automobile Drivers

\section{DISCUSSION}

This study was designed to determine and compare the prevalence of low back pain (LBP) in Commercial Motor Drivers (CMD) and Private Automobile Drivers (PAD). It was hypothesized that there would no significant difference in the 12-months prevalence of LBP among respondents in the CMD and $\mathrm{PAD}$ groups. The result showed that there was a significant difference in the 12 months prevalence of LBP between the respondents in the CMD and PAD groups. The finding of this study implies that LBP was more prevalent in the CMD group.

The observation that LBP was more prevalent among commercial motor drivers may be attributed to the longer length of time spent sitting while driving by respondents in this group compared to those in the PAD group. This finding is in agreement with the observation of Hedge (2002) and Delhi (2003), who in their separate studies reported high risk of developing LBP in men who drive at least 4 hours a day. The long hours spent sitting while driving has been found to be contributory to herniation of the lower lumbar disc, which may eventually cause low back pain as well as sciatica (Hedge, 2002).

Studies have shown that when a vehicle is in motion the body is subjected to different forces: accelerations and decelerations lateral swaying from side to side, and whole-body up and down vibrations (Hedge, 2002 and Delhi, 2003). Also, when the feet are active [i.e. when they are actively being used - the right foot on the gas (accelerator) pedal, the left on the brake, and in a stickshift also on the clutch], they cannot be used to support and stabilize the lower body as it normally happens when they are placed on the floor during normal sitting in a chair. There is evidence that the combination of these factors, coupled with the design of the car seat itself, can increase the chance of back problems for some people (Hedge, 2002)

The fact that the majority of the respondents reported having $L B P$ in the 12 -month preceding this study may suggest that LBP was a problem among the drivers, particularly among the respondents in the CMD group. This finding is in agreement with the trend in the literature and agrees with the submission of Boshuizen et al (1990), Low and Reed (1996) and Anderson (1999) that excessive periods spent driving, particularly, in a poor posture may be contributory to the deterioration of the lower 
interverbral dises with consequent pain in the low back. A high prevalence of LBP has also been reported among men who drive for at ieast 4-hours a day (Boshuizen et al, 1990; Anderson, 1999). The fact that there was a higher prevalence of LBP among the respondents in the CMD group may suggest that this group of drivers is more predisposed to LBP. This is in agreement with the reports of Boshuizen et al (1990) and Hedge (2002) that people who sit for a long time have low back problems and more disc degeneration. This finding may be attributed to the long hours spent sitting while driving by the respondents in the CMD; which might have resulted in excessive loading and tissue deformation of the lumbar spine (Boshuizen $e t$ al, 1990).

\section{CONCLUSIONANDRECOMMENDATION}

The 12-month prevalence of LBP was higher (96\%) among CMD than PAD (88\%). The participants were largely not knowledgeable about proper back care. Drivers in Nigeria will have to be educated on how to take care of their back while those who drive for long periods of time should observe breaks to relax and stretch out to reduce the incidence of LBP among them.

\section{REFERENCES}

- Andersons G. (1999): Epidemiological features of chronic low back pain. Lancet, 354: 581 - 585.

- Boshuizen HC, Bongers PM, Hulshof CT. 1990: Selfreported back pain in tractor drivers exposed to wholebody vibration. Int Arch Occup Environ Health, 62(2): 109. 15.

- Cassidyl JD (1998). Assessment of severity in low back pain disorders. Spine, 9: 204-208.
- Chen J, Chang W, Chang W and Christiani D (2005): Occupational factors associated with low back pain in urban taxi drivers. Occupational Medicine, 55(7): $535-540$.

- Cohen KB (1989). Learning Effects of a Back Education Programme. Spine, 21(19): $2183-2188$.

- Delhi R (2003): Exercise for Low back Pain. (5 $5^{\text {th }}$ edition) Oxford: Butterworth Heinemann

- Frymoyer J and Cats-Baril WL (1991). An overview of Incidences and Costs of Low Back Pain. Orthopacdic Clinic of North America., 22: 263 - 272.

- Hcdge A. (2002): Driving and Low Back Pain. American Joumal of Rehabilitative Medicine, 57(1): 26-34.

Low J and Reed A (1996): Basic Biomechanics Explained. Oxford: Butterworth Heinemann.

- Mckenzie R. (1981). The Lumbar Spine, Mechanical Diagnosis and Therapy. Waiknae: Spinal Publications.

- McKenzie R (1990). The Lumbar Spine, Mechanical Diagnosis and Therapy. Waiknae: Spinal Publications.

- Malluf K, Sahrinanns and Van D (2000). Use of a Clarification System to guide non - surgical Management of Patient with chronic LBP. Physical Therapy, 80 (11): 1097 $-1109$.

- Olaogun MOB (1999). Pathomechanics and Force Analysis at the Low Back During Physical Task. Joumal of the Nigerian Medical Rehabilitation Therapists, 4(7):7-11.

- Sinaki M and Mokri B (2000). Low Back Pain and Disorders of the Lumbar Spine. In R braddom (Ed) Physical Medicine and Rehabilitation. Philadelphia; WB Saunders: 853-893.

- Van Tulder M (2002). Pain: An Updated Review Refresher Course Syllabus. Seattle: IASP Press. 